\title{
1898, la incierta victoria de Cuba
}

\section{Luis Navarro García}

Universidad de Sevilla

La última guerra hispano-cubana comenzó en 1895 mostrando la superioridad del ejército mambí, como lo acredita la "invasión" de las provincias occidentales de la isla por Gómez y Maceo. Sin embargo, el curso de la contienda experimentó, aunque lentamente, un giro favorable a las tropas españolas, dirigidas por el general Weyler durante los dos años siguientes, restableciéndose el dominio español en casi todo el territorio al oeste de la "trocha". El cambio de gobierno a raíz del asesinato de Cánovas trajo como consecuencia un cambio de política —la concesión de la autonomía por Sagasta - y la sustitución de Weyler, víctima de una campaña de desprestigio en la misma España, por el general Blanco. Esto acarreó una demora en el inicio de la campaña de 1897-1898 y un cambio en el plan de operaciones, pero Blanco y su segundo Pando reanudaron la ofensiva, ahora sobre todo en Oriente y Camagüey, preparando una ya próxima victoria final. Esa victoria, sin embargo, les fue arrebatada a los generales españoles por la intervención norteamericana.

Es indudable que la muerte de Cánovas, presidente del gobierno español, fue el hecho que mayor influencia ejerció sobre el curso de la guerra de independencia cubana. Tras el asesinato del jefe conservador ( 8 de agosto de 1897), fuese o no el anarquista Angiolillo instrumento de los insurrectos - sobre lo que insinúan fuertes sospechas tanto Enrique Piñeyro, testigo próximo, ${ }^{1}$ como Manuel Moreno Fraginals en nuestros días- ${ }^{2}$ sobrevino, en cuestión de semanas, un giro de 180 grados en la política española respecto de la Gran Antilla. El gobierno liberal de Práxedes Mateo Sagasta se apresuró a rectificar la política de firmeza de Cánovas del Castillo para adoptar una repentina postura de apaciguamiento, tanto en el plano interno, hacia los rebeldes, como en el exterior, hacia los Estados Unidos. Política que se iría llevando hasta límites insospechables, sin haber logrado por eso evitar el desastre.

1 Piñeyro, Enrique: Cómo acabó la dominación de España en América. París, 1908, páginas 139-143, donde citando a Luis Bonafoux narra cómo el puertorriqueño Ramón Emeterio Betances, agente confidencial en París de la Delegación o Junta de Nueva York, proporcionó al asesino mil francos de los fondos cubanos en su poder.

2 Moreno Fraginals, Manuel: Cuba/España, España/Cuba. Historia común. Barcelona, 1995, pág. 238, comentando el asesinato de Prim escribe: "El pueblo cubano dejó una frase que la tradición repite: "Prim fue asesinado en Madrid, pero el gatillo lo apretaron en La Habana". La expresión parece ser cierta. (Cuando treinta años más tarde sea asesinado Cánovas del Castillo, el gatillo también será apretado en La Habana)”. Insiste en pág. 248. 
Un hombre que se hallaba en 1897 en el primer plano de la política y de la guerra, el general Weyler, expresó con absoluta claridad el sentido y alcance del magnicidio del balneario de Santa Águeda, cuando lamenta las consecuencias de la desaparición del gran político:

"consiguiendo por este medio la victoria los Estados Unidos y los insurrectos que hasta entonces no habían logrado ni era probable que lograsen por las armas ni por la diplomacia ante aquella voluntad de hierro y aquel envidiable talento". ${ }^{3}$

Se puede, por tanto, hablar de la guerra de Cuba en tiempos de Cánovas y después de Cánovas. En la primera etapa el rasgo más acusado desde el lado español es la voluntad de dominar la insurrección. Primero por ofrecimientos conciliadores (Martínez Campos) y después por la pura fuerza militar ("a la guerra con la guerra", Weyler), aunque no descartase Cánovas ciertas reformas que no le dio tiempo a aplicar. En la segunda, con Sagasta, hay un aflojamiento de la presión bélica y un intento de pacificación que sólo sirvió para que McKinley pudiese dictaminar que el ensayo autonómico había fracasado, después de lo cual sólo cabía proceder a la intervención norteamericana, gustase o no a los cubanos de entonces y de ahora.

\section{Gloria cubana, desastre español}

La Constitución cubana de 1976, en su preámbulo, alude entre otros antecesores ilustres a "los patriotas que en 1868 iniciaron las guerras de independencia contra el colonialismo español y los que en el último impulso de 1895 las llevaron a la victoria de 1898, arrebatada por la intervención y ocupación militar del imperialismo yanqui". ${ }^{4}$ Esta formulación, en un documento del máximo rango, y cuya última frase debió ser concebida como un dardo contra el irreconciliable adversario de la Cuba castrista, contiene no sólo una muestra de desagradecimiento contra quienes contribuyeron de manera decisiva a liquidar "el colonialismo español" en Cuba, sino una aseveración más que discutible y para el objetivo de estas páginas más importante: la supuesta victoria de los separatistas en 1898.

Semejante afirmación tiene unos claros antecedentes y una comprensible motivación. Están los antecedentes en la apreciable labor historiográ-

3 Weyler, Valeriano: Mi mando en Cuba (10 febrero 1896 a 31 octubre 1897). Madrid, 1910, 5 vols.; tomo V, pág. 20.

4 Esta cláusula no fue modificada por la reforma constitucional que tuvo lugar en 1992. 
fica "revisionista" desplegada por historiadores como Herminio Portell Vilá y, más aún, Emilio Roig de Leuchsenring y Benigno Souza y Rodríguez, ${ }^{5}$ que sentaron la tesis del fracaso militar español previo a la intervención yanqui, y no sólo la sostuvieron, sino que la hicieron aprobar en congresos de historiadores, y por lo tanto insertar en los libros de texto cubanos como verdad demostrada. Desde entonces se dirá en esos textos como cosa sabida que en 1898, antes - para ellos esto es lo importante- de que los Estados Unidos entraran en el escenario bélico, España estaba agotada y había consumido hasta "el último soldado y la última peseta", según la frase que, con distintas variantes, saliera de labios de Sagasta y de Cánovas. ${ }^{6}$ Entre los acuerdos aprobados por los Congresos Nacionales de Historia II y VII (La Habana, 1943 y 1948), al producirse la Resolución Conjunta del Congreso de Washington sancionada por McKinley "Cuba estaba irremisiblemente perdida para España". ${ }^{7}$ Y hallándose España en definitiva postración, la victoria estaba al alcance de la mano del ejército mambí y puede ser adjudicada póstumamente al general Calixto García Sánchez. El general, sin embargo, por lo que sabemos, murió poco después de concluir las hostilidades ignorante de haber sido el vencedor.

La motivación de tal proceder por parte de historiadores y políticos cubanos ha sido bien explícita: el acuerdo $1 .^{\circ}$ del citado Congreso proclama que "Cuba no debe su independencia a los Estados Unidos", ${ }^{8}$ y Roig de Leuchsenring declaró sin ambages el impulso patriótico que lo llevaba a luchar en defensa de semejante tesis:

"Contra el derrotismo, basado en una falsa visión de la realidad, que ha provocado un funesto complejo de inferioridad en nuestro pueblo, puede asegurarse que la Guerra de Independencia de 1895 fue una guerra victoriosa de Cuba contra España".

5 Puede consultarse sobre el particular, aunque tenga un planteamiento distinto del nuestro, el trabajo de Gonzalo Zaragoza Ruvira: "Tres interpretaciones de la Guerra de Independencia cubana". Revista de Indias, n. ${ }^{\circ}$ 147-148, Madrid 1977, págs. 249-264.

6 La misma idea con diferentes palabras había sido repetida en distintas ocasiones desde que la formulara en 1869 Manuel Becerra, ministro de Ultramar. Rubio, Javier: La cuestión de Cuba y las relaciones con los Estados Unidos durante el reinado de Alfonso XII. Los orígenes del "desastre" de 1898. Madrid, 1995, pág. 154, nota 8.

7 Punto 17 de los acuerdos del VII Congreso. El texto de estos acuerdos aparece como apéndice en varias obras de Emilio Roig de Leuchsenring: 1895 y 1898. Dos guerras cubanas. Ensayo de valoración, La Habana, 1945; Triunfo del esfuerzo cubano por la independencia, La Habana, 1948; Reivindicaciones históricas, La Habana, 1949; La guerra libertadora cubana de los treinta años, La Habana, 1952.

8 Roig puso este discutible título a una de sus obras, publicada en La Habana, 1950.

9 Roig de Leuchsenring, Emilio: 13 conclusiones fundamentales sobre la Guerra Libertadora Cubana de 1895. México 1945, pág. 32. 
Por otra parte, cabe adelantar una explicación de cómo se pudo llegar a la fijación de ese clisé que pretendidamente define la guerra de 1895 al 98 como victoria cubana y derrota española. El punto de partida objetivo es que España tuvo que abandonar Cuba. A partir de aquí se podría debatir acerca de qué responsabilidad cupo a los insurrectos en este hecho. Y para probar que su responsabilidad fue grande basta esgrimir, por paradójico que resulte, ciertas informaciones periodísticas españolas, ciertos discursos de políticos españoles, en los que, a lo largo de 1897 —insistimos en la fecha, 1897-, se fue creando la imagen de un fracaso militar en Cuba, fracaso tal vez ocultado por las informaciones falsas proporcionadas al mismo gobierno español por el capitán general Weyler. Eso explica el cambio de política sobrevenido tras la desaparición de Cánovas: era urgente buscar un modo de reconciliación política, toda vez que el recurso a la guerra no había dado resultado. Esa es la sencilla explicación que por entonces dio Piñeyro: "Como Weyler evidentemente ni cumplía ni podía ya cumplir la pacificación prometida...”. ${ }^{10}$

Es muy fácil construir un discurso que enlace la gloria de los "invasores", el heroísmo de Maceo y la genial estrategia de Gómez, con la penosa estampa de los soldados españoles repatriados, los que lograron sobrevivir, después de haber sufrido toda clase de penalidades y padecimientos. El triunfo militar cubano parece así reconocido.

\section{La “invasión” y el culto a Maceo}

La historiografía cubana tiene unos jefes militares que contraponer a los españoles, unos éxitos o victorias que prueben la aptitud bélica de sus soldados y generales y hagan creíble la derrota española. El triunfo cubano sería, además, tanto más meritorio por haberse alcanzado en condiciones de inferioridad por el número de combatientes, el ningún adiestramiento de éstos, la escasez de armas y municiones, etc. A pesar de eso, sus dos grandes figuras militares, Máximo Gómez y Antonio Maceo, alcanzaron repetidas victorias: el paso de la "trocha", la penetración hacia Occidente, una serie de encuentros, desde los de Peralejo y Mal Tiempo hasta el de Coliseo, la contramarcha o "lazo" de la invasión, las correrías por la provincia de La Habana, la entrada en Pinar del Río, hasta Mantua...

10 Piñeyro: ¿Cómo acabó..., pág. 152. 
La exaltación de esta campaña es tema obligado. Tal vez la mejor muestra la proporcione José Luciano Franco:

"En el salón de actos del Ayuntamiento de Mantua, en sesión solemne presidida por el general Maceo, se levanta el acta haciendo constar el término de la Campaña de Invasión. En 90 días, desde Baraguá, Oriente, en 78 jornadas ha hecho Maceo con sus mambises 424 leguas, después de sostener 27 combates y ocupar 22 pueblos importantes, 2.120 fusiles y 82.000 cartuchos quitados a los españoles, consumándose, como dijera Clarence King, en revistas belga y americana, el plan militar más audaz. de la centuria...".

Según Philip S. Foner, que recoge cifras parecidas y la cita de King, "todos decían que la Campaña de Invasión era un logro remarcable. Un historiador militar la ha comparado con la de Aníbal en Italia y las marchas de San Martín, Sherman y Napoleón". ${ }^{22}$ Por su parte, la Historia de Cuba de las Fuerzas Armadas Revolucionarias transcribe un comentario del periódico norteamericano "The Sun", según el cual "la habilidad de la estrategia del jefe revolucionario jamás ha sido sobrepujada en una guerra... (La Invasión) se acerca más a los prodigios de la leyenda que a los anales auténticos de nuestro tiempo. Gómez ha desplegado en toda esta campaña admirable genio militar". Y en la misma obra se reproduce un juicio del general norteamericano Sickles, para quien "La marcha de Gómez, desde el punto de vista militar, es tan notable como la de Sherman... debemos poner a Gómez y a Maceo en la primera fila de la capacidad". ${ }^{13}$

No es nuestro propósito poner en duda la competencia de Gómez y Maceo, sino sólo llamar la atención acerca de los elogios, que rayan en lo hiperbólico, que se les dedican. Elogios que resultan comprensibles en el clima de exaltación producido por la misma guerra, pero no tanto una vez transcurridas varias décadas, aproximándose al cumplimiento del siglo. Llamar "invasión" a una incursión realizada por unos 4.000 hombres ya es magnificar la empresa con fines propagandísticos. Comparar esta empresa con las de Aníbal, San Martín o Napoleón resulta sencillamente desproporcionado, tratándose de operaciones de muy diferente carácter y circunstancias y de algunos de los jefes militares de mayor categoría histórica; la equiparación con Sherman, aparte de su desmesura, podría no resultar pre-

11 Franco, José Luciano: La vida heroica y ejemplar de Antonio Maceo (Cronología). La Habana, 1963, págs. 103-104.

12 Foner, Philip S.: La guerra hispano/cubano/americana y el nacimiento del imperialismo norteamericano. 1895-1902, Madrid, 1975, 2 vols., I, pág. 112.

13 Dirección Política de las FAR: Historia de Cuba, La Habana, 1981, pág. 411. 
cisamente elogiosa. Y puestos a buscar paralelos, a nadie se le ocurrió establecer uno con las "invasiones" de Hernán Cortés y Pizarro y algunos otros conquistadores o, todavía más fácil, con las "expediciones" realizadas por los carlistas sobre territorio enemigo durante las guerras civiles en la Península.

Pero la observación más importante para nuestro objeto es la de que, sea cual fuere el valor de esta campaña victoriosa de 1895-1896, constituye un episodio excepcional en el curso de la guerra. La larga incursión de Gómez y Maceo fue posible por toda una serie de factores - la sorpresa, la impreparación y dispersión de las tropas españolas - entre los que destaca uno principal: los "invasores", conscientes desde el principio de su neta inferioridad para la lucha en campo abierto, rehuían el combate con las columnas de Martínez Campos y en cambio atacaban, aprovechando su superioridad numérica en un punto concreto, poblados prácticamente desguarnecidos. Así lo afirma Francisco Pérez Guzmán hablando de los asaltos realizados durante la Invasión:

"La táctica fundamental radicaba en la enorme superioridad numérica de los mambises en relación con las guarniciones de los centros urbanos, la vigilancia de las columnas enemigas para impedir un cerco y la inexistencia de estructuras defensivas adecuadas para proteger las zonas urbanas". ${ }^{14}$

Superioridad numérica y ausencia de fortificaciones son dos de los factores del retroceso español de 1895. Hay otro más que parece insinuado en la anterior cita: la movilidad de las fuerzas mambisas, con amplio predominio de caballería, frente a las lentas columnas españolas integradas básicamente por infantería. Uno de los reproches que luego se harán a Martínez Campos se refiere al descuido que tuvo al no recoger todos los caballos, permitiendo que se apoderasen de ellos los insurrectos, como no sin petulancia lo dijo Bernabé Boza, colaborador inmediato de Gómez:

"Nuestra caballería ha mejorado mucho. Al atravesar la provincia de Matanzas nos hemos apoderado en ella de todos los caballos buenos y útiles que encontramos a nuestro paso, y con ellos hemos repuesto los nuestros, cansados e inservibles. La estúpida confianza y el quijotesco orgullo de los generales españoles, que aseguraban era imposible que llegáramos aquí, así como la falta de previsión del general Martínez Campos no haciendo recoger y retirar a tiempo, como pudo hacerlo, este elemento de guerra y de transporte de que tan buen uso sabemos hacer nosotros y que por doquier

14 Pérez Guzmán, Francisco: La guerra de liberación. Máximo Gómez. La Habana, 1986, pág. 100. 
encontramos, ha sido, y así lo consignará un día la Historia, una de las principales causas de nuestro éxito y de nuestro triunfo". ${ }^{15}$

No hay misterio, por tanto, en el sorprendente éxito mambí de 1895. La situación se invertirá cuando el capitán general de La Habana pueda contar con más tropas $-\mathrm{y}$ tropas entrenadas y familiarizadas con el nuevo fusil Mauser, lo que no ocurría al principio-, cuando los poblados empiecen a defenderse con fuertes, trincheras y alambradas, y cuando la caballería española se reorganice en regimientos completos, capaces de operar por sí solos contra los insurrectos.

La balanza, antes absolutamente desnivelada, se fue reequilibrando a lo largo de 1896. La estrella de Gómez empezó a palidecer. La de Maceo, aunque alcanzó su máximo esplendor durante unos meses en Pinar del Río, se apagó definitivamente el 7 de diciembre en el combate de San Pedro, en la provincia de La Habana, una vez que las tropas españolas habían debelado su reducto del Rubí, en la sierra del Rosario, donde se ve acosado desde el 20 de marzo, ${ }^{16}$ hasta que el 10 de noviembre es desalojado por la acción convergente de las columnas de Weyler. ${ }^{17}$

\section{La progresión de Weyler hasta La Reforma}

La muerte de Maceo, fruto de la incesante persecución de los mambises que Weyler impulsó a ambos lados de la trocha de Mariel, marca con claridad un punto de inflexión en el curso de una guerra en la que, por sus características, nunca se darían grandes combates ni se alcanzarían resonantes victorias. Pero el ejército mambí había tenido dos jefes y ahora sólo quedaba uno. La caída de Maceo, todos lo adivinaron de inmediato, significaba un decisivo retroceso de la insurrección no solo en Pinar del Río, sino también en La Habana y Matanzas, por lo menos, y esto era un grave descalabro para Gómez, cuyo plan había sido, precisamente, el de ganar para la insurgencia las provincias occidentales y privar a la metrópoli de los recursos que de ellas obtenía.

15 Boza, Bernabé: Mi diario de la guerra, La Habana, 1924, 2 vols., I, 2. parte, pág. 125. Anotación correspondiente al 2 de enero de 1896.

16 Así lo anota el jefe de Estado Mayor de Maceo, el catalán José Miró Argenter: Cuba: crónicas de la guerra, La Habana, 1945, 4. ${ }^{\text {a }}$ ed. en 1 vol., 2. ${ }^{a}$ parte, págs. 172-173.

17 El 10 de noviembre se hizo el asalto a la bayoneta, dice Weyler, "quedando yo a las 4 de la tarde dueño de todas las posiciones del Rosario, centro del Rubí’. Weyler: Mi mando..., t. III, pág. 9. 
Para entonces, el plan de Weyler estaba funcionando a la perfección. Sus tropas regulares habían alcanzado una cifra superior a los 200.000 hombres -el mayor ejército jamás enviado a América por una potencia europea-, a los que se sumaban los voluntarios y guerrillas locales, y llegaría el momento en que el capitán general pidiera que no se le enviasen más refuerzos, ni siquiera para reponer las bajas naturales. Estaba seguro de que con esas tropas, ya bastante experimentadas y aclimatadas, podía cumplir su compromiso de acabar la guerra a principios de 1898. Además de la trocha de Mariel, había reconstruido y completado la de Júcaro a Morón, prolongada a través de la laguna de la Leche, donde situaría lanchas armadas, hasta la isla de Turiguanó. Esta trocha de Oriente se haría para Gómez tan invulnerable como la de Mariel lo fuera para Maceo.

Además de arrinconar y batir a Maceo en Oriente, Weyler había dividido en zonas las provincias centrales, situando en cada una una columna de batallón encargada de batir continuamente ese distrito para limpiarlo de mambises. Ya no serían precisas largas persecuciones y los soldados se familiarizarían con la región en la que operaban. Los insurrectos no aparecían ya en grandes contingentes, sino en pequeñas partidas que rehuían el combate.

Weyler ordenó además la destrucción de todos los asentamientos de los rebeldes y de todo aquello que pudiera servirles para subsistir: viviendas, talleres, siembras, ganados, etc. Ya había empezado a hacerlo en Pinar del Río, cuando las tropas comenzaron a talar los platanares de la sierra del Rosario. Los mambises llamaron a esta operación "la campaña de los plátanos" para ridiculizarla, pero lo cierto es que, privando a los insurrectos de sus habituales recursos alimenticios, buscaba Weyler obligarles a salir de sus escondrijos para combatir o para presentarse de paz, y muy pronto empezaron a advertirse estos efectos en la mayoría de las provincias.

Los "bandos de reconcentración" forman parte de este mismo sistema de guerra. Impidiendo la labor de espionaje o de socorro que los "pacíficos" habían desarrollado voluntaria o forzadamente en el primer año de la guerra - lo que tanto había desmoralizado a Martínez Campos- se dificultarían en gran medida las actividades de las partidas insurgentes. ${ }^{18}$ No es

18 Carlos Serrano dice que "Weyler inauguró la que prácticamente iba a ser la primera guerra antiguerrilla de la historia, tratando de quitarle el agua al pez". Serrano, Carlos: Final del Imperio. España 1895-1898. Madrid, 1984, pág. 27. Generalmente se recuerda que la misma orden de reconcentración impusieron poco después los ingleses en el Transvaal y los norteamericanos en Filipinas. Robles Muñoz añade la aplicación de esta medida por los franceses en Madagascar. Robles Muñoz, Cristóbal: "Triunfar en Washington. España ante Baire". Anuario de Estudios Americanos, XLIX, Sevilla, 1992, págs. 563-584. 
del caso ponderar los sufrimientos y mortandad que esto produjera a la población civil. Era una medida de guerra ya aplicada en la Guerra de los Diez Años por el conde de Valmaseda, a cuyas órdenes sirvieron un tiempo Weyler y Martínez Campos, que la describió perfectamente, sintiéndose sin embargo sin ánimos para ponerla en vigor. Ahora Weyler lo hará, contribuyendo con ello a asentar la superioridad de sus fuerzas y, como dirá un documento oficial español, con una finalidad humanitaria: la de abreviar la duración del conflicto. Parte de los fallecimientos ocurridos en las zonas de concentración se deberían, según el mismo Weyler, a la absoluta depauperación física con que se presentaban muchos individuos y familias que habían permanecido meses pasando hambre con los rebeldes.

Las operaciones militares de mayor envergadura, ya en 1897, tomaron una orientación muy decidida: la marcha desde Pinar del Río y La Habana hacia la trocha de Júcaro, contra la que queda acorralado Gómez, como antes lo fuera Maceo en la sierra pinareña.

"Al lado oeste (de la trocha) — dice Fernando Portuondo- Máximo Gómez resistía el embate del ejército español en operaciones. Fraccionados e incapacitados para organizar una campaña ofensiva, los insurrectos se sostenían en las comarcas occidentales refugiándose en las peores circunstancias en las sierras y los pantanos". Pero este mismo autor escribe algo después que Gómez "se propuso burlarse del jefe español, al mismo tiempo que librar a los insurrectos de la mitad occidental de la isla de la persecución de que eran objeto", y para ello "planeó Máximo Gómez entonces la genial campaña de La Reforma, llamada así porque tuvo como centro el potrero de ese nombre. Ideó atraer grandes fuerzas adversarias sobre sí mismo, y batirlas y entretenerlas en una zona de apenas diez leguas cuadradas, que abarcaba como la tercera parte de la región comprendida entre la trocha de Júcaro a Morón y los dos Jatibonicos". ${ }^{19}$

La verdad es que esta campaña de La Reforma, o de Las Villas, ${ }^{20}$ no fue, casi desde el principio, sino una desesperada defensa por parte de Gómez que, más afortunado que Maceo, logró sobrevivir al prematuro término del gobierno de Weyler. La enaltecedora historiografía cubana enfatiza la habilidad del "generalísimo" para escapar del cerco, para atraer a los españoles a lugares enfermizos, para no dejarles descansar, etc., así como

19 Portuondo del Prado, Fernando: Historia de Cuba hasta 1898, La Habana, 1965, páginas 562-563.

20 Dirección Política de las FAR: Historia..., pág. 457. 


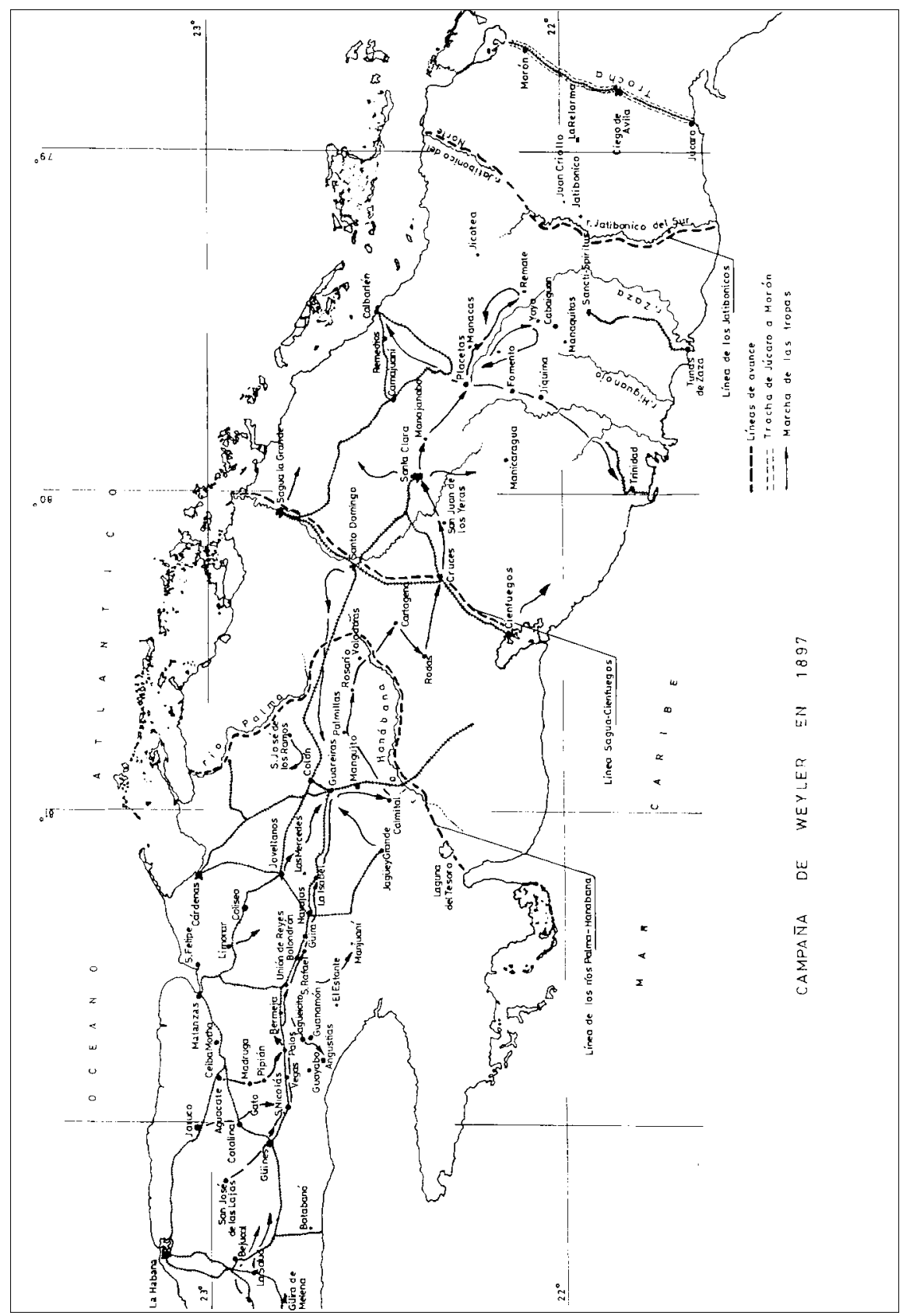

174 
su maniobra de distracción para hacer creer que intentaba una nueva marcha hacia Occidente. ${ }^{21}$

Un estudio más moderno y ponderado, sin embargo, advierte la disminución de combates en que interviene Gómez, desde la cifra de 48 en 1896, hasta la de 23 en 1897, y a 7 en los pocos meses de actividad de 1898. "Las causas de un descenso en sus hechos de armas en 1897 y 1898 están dadas en la carencia de material bélico, lo que incidió en la concepción de la campaña de La Reforma", manteniendo al enemigo en continuo movimiento pero sin entablar combate, y esto en un territorio de no más de 160 kilómetros cuadrados. La partida que manda ahora Gómez tiene menos de 300 hombres. "Los encuentros armados con menos de 300 hombres pertenecen casi todos a la campaña de la Reforma y a los últimos meses de la guerra de 1898 - etapa de resistencia sin recursos bélicos y sometido a una persistente persecución por las columnas españolas". ${ }^{22}$ En estas líneas se reconoce la eficacia de la vigilancia por mar y tierra de las fuerzas de Weyler para impedir la llegada de expediciones filibusteras a los rebeldes.

Por otra parte, las verdaderas intenciones de Gómez a principios de 1897, que alguna historiografía trata de encubrir, podían ser realmente las de llevar a cabo una nueva incursión sobre Matanzas y La Habana. Lo cierto es que Gómez, que estaba en Camagüey, ignorando aún la muerte de Maceo, pasó la trocha al norte de Morón con 400 hombres en los últimos días del año 1896. La campaña de la Reforma comenzó con el ataque al poblado fortificado de Arroyo Blanco, próximo a la trocha, el 27 de enero. Su propósito era reanimar la insurrección en Occidente enviando refuerzos, lo que no pudo lograr, en parte por la creciente resistencia de los mambises de Oriente a pasar la trocha, y en parte por la rápida acción de Weyler disponiendo un desplazamiento general de sus columnas de Oeste a Este, desde Pinar del Río hasta la línea de los ríos Hanábana y Palma, que separan Matanzas de Las Villas, donde ya se hallaba instalado en la última semana de enero. Allí hizo construir doce fortines, y seis más al norte de la Ciénaga, para impedir el paso de partidas hacia Matanzas. Difícilmente podía Gómez aliviar la presión que ejercía Weyler sobre los rebeldes de las provincias occidentales, donde la persecución se mantenía incesante, así como la reconcentración de personas, la recogida de ganado y la destrucción de otros bienes, siguiendo las instrucciones del capitán

21 Ibídem, págs. 458-462.

22 Pérez Guzmán: La guerra..., págs. 22 y 27. 
general. ${ }^{23}$ Tan seguro estaba éste del grado de pacificación alcanzado, que autorizó la zafra en las tres provincias occidentales, y poco después en Las Villas, sabiendo ya que los dueños de plantaciones e ingenios no serían obligados a pagar contribución por los insurrectos.

Pocos días después, habiendo rebasado la línea de Sagua, Santa Clara y Cienfuegos, avanza el 11 de febrero a la de Caibarién a Trinidad, por Remedios, Placetas, Fomento y Jiquima y dispone operaciones sobre la Siguanea y el Escambray. Gómez va a quedar encerrado entre los ríos Jatibonicos Norte y Sur y la trocha. Es ahora cuando el Consejo de Gobierno rebelde, que estaba con él, regresa a Oriente aprovechando el paso todavía no cerrado al norte de Morón. Esto no impide a un autor escribir que

"los rebeldes mandados por Gómez se movían con toda libertad, sin que los españoles fueran capaces de desalojarlos o de infligirles pérdidas decisivas. En la campaña de la Reforma, Weyler fue decisivamente vencido por Gómez" ${ }^{24}$

La realidad es que desde marzo se intensifica el acoso de Gómez en la Reforma, causándole importantes bajas, aunque el jefe rebelde no pudiera ser capturado ni abatido; que Weyler empieza a colocar blocaos en la costa sur de Las Villas —en La Broa, Cazones y Bahía de Cochinospara impedir la llegada de expediciones filibusteras, y que Quintín Banderas, que todavía logró pasar por los esteros de Turiguanó con 150 hombres y 50 caballos, fue varias veces batido juntamente con Carrillo y su fuerza enteramente dispersada a mediados de abril, frustrándose su marcha hacia Matanzas según el plan de Gómez. Detrás de Banderas debía cruzar la trocha Calixto García, pero la gente que había reunido desertó negándose a seguirle, aunque se les había dicho que sólo irían a Camagüey. En mayo Weyler dirige el rastreo del reducto de Gómez sin hallarlo, y al mismo tiempo va completando el sistema de comunicaciones de la

23 Instrucciones de 8 de enero de 1896, punto 5. : "En resumen, lo que espero de las columnas y guerrillas y demás fuerzas armadas es que contribuyan del modo más rápido posible a quitar... los recursos que el enemigo pueda utilizar por no estar suficientemente protegidos, para obligarle a que la falta de alimentos le haga salir de sus guaridas a batirse o entregarse". Weyler: Mi mando..., t. III, págs. 295-296.

24 Esta es la parte esencial del único párrafo que a la campaña de Weyler en 1897 dedica Foner (I, pág. 168). Ya se ve a qué llama "vencer decisivamente" por parte de Gómez, mientras pondera que los españoles no le causaron "pérdidas decisivas", que no pueden obtenerse en este tipo de guerra, no siendo la muerte del mismo jefe, como en el caso de Maceo. También niega que estuviera pacificado el Occidente porque alguna vez se producía el asalto de un pueblo o la voladura de un tren, cosa difícil de impedir a corto plazo. 
zona - ferrocarril, telégrafo, heliógrafo-, mientras se va recogiendo el ganado que allí abundaba, y destruyendo las siembras de los rebeldes. "En el campo no queda con qué vivir", dice Weyler en un informe al ministro de la Guerra de 10 de junio. ${ }^{25}$ A finales de este mes se podía considerar concluida la pacificación de Occidente, aunque todavía subsistiese la partida de Gómez ${ }^{26}$ y alguna otra en La Habana, cuya destrucción se produciría a corto plazo.

\section{El proyecto final y la crisis de agosto}

A mediados de 1897, entrando ya la estación de aguas que obligaba a paralizar las operaciones militares, Weyler se prometía acabar la guerra en pocos meses a partir del cese de las lluvias. Tan es así que empezó a estudiar el envío de parte de sus fuerzas a Oriente, al otro lado de la trocha, para ir tomando posiciones allí con vistas a la que debía ser la última campaña contra los insurrectos. En julio dio instrucciones para reducir al mínimo los puestos guarnicionados en Oriente, puestos o poblados que carecían de importancia o de valor estratégico. Se ahorraban así muchos destacamentos de escasa utilidad, que absorbían tropas y eran costosos de mantener y aprovisionar. Entre otras cosas, Weyler, que conocía bien la provincia de Oriente, donde había combatido en la "guerra larga", descartaba operar en la región del río Cauto, aunque conservaría Manzanillo y Bayamo, y proyectaba establecer en este sector algunos poblados y fuertes, y trasladar otros, para asegurar las comunicaciones. Entre junio y julio visitó Manzanillo y Santiago para hacerse cargo de la situación sobre el terreno y conferenciar con los jefes de la zona. ${ }^{27}$ Llegó a enviar dos batallones para comenzar la limpieza del distrito de Baracoa.

A principios de julio había proyectado operar en la provincia de Santiago de Este a Oeste, según anunciara desde el principio, es decir, des-

25 Weyler: Mi mando..., t. IV, págs. 433-436. Sobre la desastrosa situación del ejército mambí por hambre, enfermedad y desnudez en 1897 y 1898, a consecuencia de la reconcentración de los pacíficos, véanse los testimonios recopilados por Poumier, María: Apuntes sobre la vida cotidiana en Cuba en 1898, La Habana, 1975, págs. 59-97.

26 Subsistía la partida de Gómez porque éste no había podido pasar la trocha, operación que los insurrectos prepararon para primeros de agosto, convencidos de que no podían aliviar la situación del generalísimo ni reavivando la rebelión en Occidente, ni enviándole hombres y municiones que de ningún modo le podían llegar. Weyler: Mi mando..., t. IV, pág. 514.

27 Weyler: Mi mando..., t. IV, págs. 440 y 503. 


\section{LUIS NAVARRO GARCÍA}

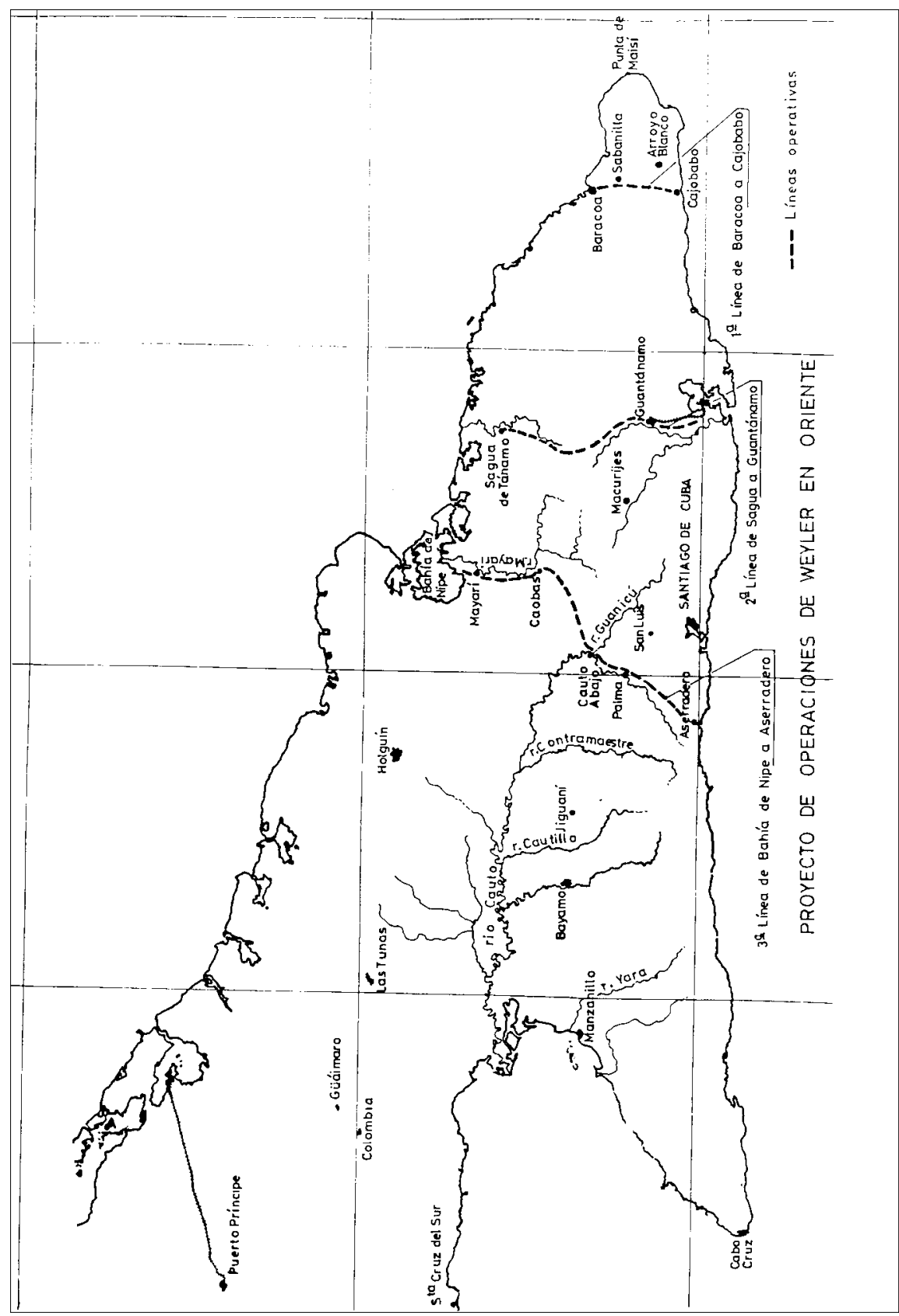

178 
de el cabo Maisí hacia la trocha de Júcaro. ${ }^{28}$ Los primeros movimientos debían proporcionarle la ocupación del territorio desde el cabo Maisí hasta Cauto Abajo, importante cruce de caminos. En el territorio intermedio establecería tres líneas de costa a costa: la primera, de Baracoa a Cajobabo por Sabanilla; la segunda, de Sagua de Tánamo a Guantánamo, y la tercera desde la bahía de Nipe al Aserradero, siguiendo el curso de los ríos Mayarí y Cauto. ${ }^{29}$ Pronto determinaría los puntos de desembarco de los veinticinco batallones, más artillería y otros efectivos que enviaría a Oriente, así como dispondría de los barcos que debían realizar el transporte, más un buque hospital para retirar heridos graves.

Es posible que la proximidad de la completa victoria de Weyler exacerbase la campaña desplegada contra él por la prensa norteamericana y la prensa liberal española, que se alimentaban mutuamente. Dicha campaña, aparte de la denuncia de los procedimientos represivos aplicados por el general, adoptó además la táctica de negar su eficacia, y como Weyler mostrara el balance positivo de su labor — la pacificación de Occidente-, se añadió contra él la acusación de mentiroso. El gobierno de Cánovas no podía perder de vista el persistente interés del gobierno norteamericano por intervenir en los asuntos de Cuba, y por eso, al tiempo que le urgía para que concluyese la guerra - lo que no podía ocurrir mientras durase la estación de lluvias - había dictado en febrero de 1897 un decreto de reforma y descentralización administrativa ${ }^{30}$ que Weyler se disponía a poner en vigor en las provincias ya pacificadas. El general, por su parte, hacía nuevos ofrecimientos de perdón y ayuda a los presentados, trataba de asegurar la manutención de los reconcentrados y proyectaba obras públicas para crear puestos de trabajo para estos, muchos de los cuales habían ingresado en las guerrillas, donde prestaban buenos servicios. ${ }^{31}$

28 Este planteamiento de la campaña coincide en lo esencial con el que en situación semejante propuso Valmaseda en 1869: concentrar los esfuerzos en Las Villas y Oriente; cuando estos dos territorios estuviesen pacificados, caer sobre Camagüey y sofocar la rebelión en quince días. Valmaseda a Caballero de Rodas. Santiago 7 de diciembre de 1869. En Muñoz de las Heras, Agustín: La crisis cubana en el arranque del sexenio democrático, tesis inédita, Universidad Complutense, 1986, 2 vols., t. II, pág. 995.

29 Weyler: Mi mando..., t. IV, págs. 505-506, y t. V, págs. 39-40.

30 En el preámbulo del decreto (Serrano, págs. 145-151) dice Cánovas que ya antes el gobierno había declarado "que no aguardaría a que desapareciese el último insurrecto de Cuba, bastándole que la final victoria pareciese asegurada y estuviese el honor satisfecho, para atender a la real necesidad que la isla siente de experimentar lo que los ingleses titulan self government, o sea, una descentralización amplia...". Para una autora reciente, el decreto de Cánovas representaba el fracaso de toda la política monárquica desde hacía veinte años”. Roldán de Montaud, Inés: La Unión Constitucional y la política colonial de España en Cuba (1868-1898). Madrid, 1991, pág. 677.

31 Weyler: Mi mando..., t. IV, págs. 401-403. 
Pero los ataques más fuertes contra él vinieron del partido liberal. Su jefe, D. Práxedes Mateo Sagasta, afirmaría en un discurso: "Después de haber enviado 200.000 hombres y de haberse derramado tanta sangre, no somos dueños en la isla de más terreno que el que pisan nuestros soldados". Falsedad que, recogida de boca tan autorizada, inmediatamente se esgrimiría en Washington para probar que, efectivamente, Weyler había fracasado. Por su parte, Silvela, conservador disidente del grupo de Cánovas, diría que "una política nueva debía hacerse por otro hombre que no fuera Weyler", y que "era preciso ir a la liquidación del asunto". Pero fue Segismundo Moret quien llegó a admitir en el Senado la posibilidad de que Weyler mintiese en sus informes acerca de la buena marcha de las operaciones. Cánovas se vio obligado a responder el 31 de mayo que "el gobierno no puede partir de la idea de que un General en Jefe español delante del enemigo oculte la verdad a su gobierno y a su Patria...". Por lo demás, había pruebas de todo tipo del éxito logrado hasta entonces: nadie negaba que los trenes circulaban libremente entre Pinar del Río y Las Villas; Weyler había pedido que no se le enviasen más reemplazos, ni siquiera para reponer las bajas, y estaba enviando soldados a la península... Los generales que llegaban de Cuba decían que la guerra estaba terminada, por lo menos en los departamentos aludidos... El mismo general Lee (cónsul norteamericano en La Habana) había reconocido espontáneamente la impotencia de la insurrección... ${ }^{32}$

Esto no obstante, la tormenta política seguía arreciando durante el verano. Silvela aseguraba en un discurso en Burgos que se gobernaba Cuba "asolándola, destruyéndola, sujetándola al más funesto rigor". Esto cuando toda la porción occidental, la más rica, estaba en condiciones de hacer su zafra y cosechar el tabaco. Moret insistiría en Zaragoza en que "se aplica la política de la destrucción y el exterminio..., la fuerza sin atenuaciones ni misericordia..., asolando y devastando", describiendo en tono melodramático los campos desolados, la reconcentración, las ejecuciones y el incen-

32 Discurso transcrito en Ibídem, t. IV, pág. 497-501. El historiador norteamericano Foner (I, pág. 167) reprocha a su compatriota Walter Millis el haberse creído las fanfarronadas de Weyler cuando aseguró que con la muerte de Maceo la situación de Pinar del Río quedaba bastante aclarada. Con igual razón cabría decir que Foner se ha creído la propaganda de la Junta de Nueva York y los ataques políticos a Weyler; además, como otros, ignora prácticamente la campaña de 1897, pasando de la muerte de Maceo al resurgimiento de la insurrección en 1898. Por cierto que en el mismo lugar indica Foner que ya en marzo y abril de 1897 el cónsul Lee escribía al secretario de Estado Sherman que Weyler publicaba informes falsos que impedían al mismo gobierno español conocer la verdadera situación en Cuba. 
dio de viviendas. Como dice Weyler, Moret debería haber visitado Cuba para conocer aquello de que hablaba. Y todavía este mismo político, del que Weyler se declara admirador, proclamaba: "el partido liberal entiende que la fórmula necesaria para lograr este resultado es una: la autonomía de la isla de Cuba".

El oportunismo dictaba estas frases que habían de servir para justificar las protestas humanitarias del gobierno de Washington y para que los modernos historiadores atestigüen el horror y el fracaso de los métodos de Weyler. Pero no habrán de pasar muchos meses antes de que el mismo Sagasta, desde la presidencia del gobierno, asuma como positiva la obra del penúltimo capitán general de la isla. En cuanto a la fórmula política propuesta enfáticamente por Moret, basta recordar que el partido liberal no respaldó la posible autonomía de Cuba, ni antes de Baire, ni inmediatamente después, cuando estaba en el poder, habiendo aceptado luego como necesario el relevo de Martínez Campos por Weyler.

En esta tesitura, cuando el gobierno español intentaba acelerar la conclusión de la guerra, evitando al mismo tiempo la injerencia en ella de los Estados Unidos, sobrevino el 8 de agosto el asesinato de Cánovas. El partido conservador se mantuvo en el poder unas semanas, bajo la presidencia del general Azcárraga, fiel a las directrices de su antecesor, pero a principios de octubre la reina regente consideró oportuno poner el gobierno en manos del partido liberal. Sagasta sería el presidente y Moret el ministro de Ultramar. A demanda de Weyler, que aludía a las censuras que antes le habían dirigido estas personas, respondió Sagasta que no le negaba su confianza, pero que el cambio de política que iba a introducir requería contar con personas identificadas con él. El 9 de octubre le comunicaba el cese, acogido con enorme clamor por cuantos en Cuba creían que de la permanencia de Weyler en el mando dependía el mantenimiento de la isla dentro de la Monarquía española. Se completaba así el inevitable cambio originado por la desaparición de Cánovas. ${ }^{33}$

33 Foner critica (I, 176) a los historiadores que creen que el relevo de Weyler se debió a la presión de Washington, "ignorando el hecho de que el fracaso de las operaciones militares en Cuba fue un factor decisivo", y alega para ello un artículo de El Heraldo de Madrid, de clara tendencia liberal, de 17 de noviembre, que da a entender que no era cierta la pacificación de ninguna provincia de la isla y que con Weyler se hubiera perdido la colonia. Una vez más le reprocha a Millis dar por buenas las declaraciones de Weyler "que ningún contemporáneo se creía”. Pero aunque esto fuera así, cabe admitir que Weyler dijera la verdad y sin embargo sus adversarios hubieran ganado la batalla propagandística. De que esto último no era totalmente cierto da idea el triunfal recibimiento que se hizo a Weyler a su regreso a España. 


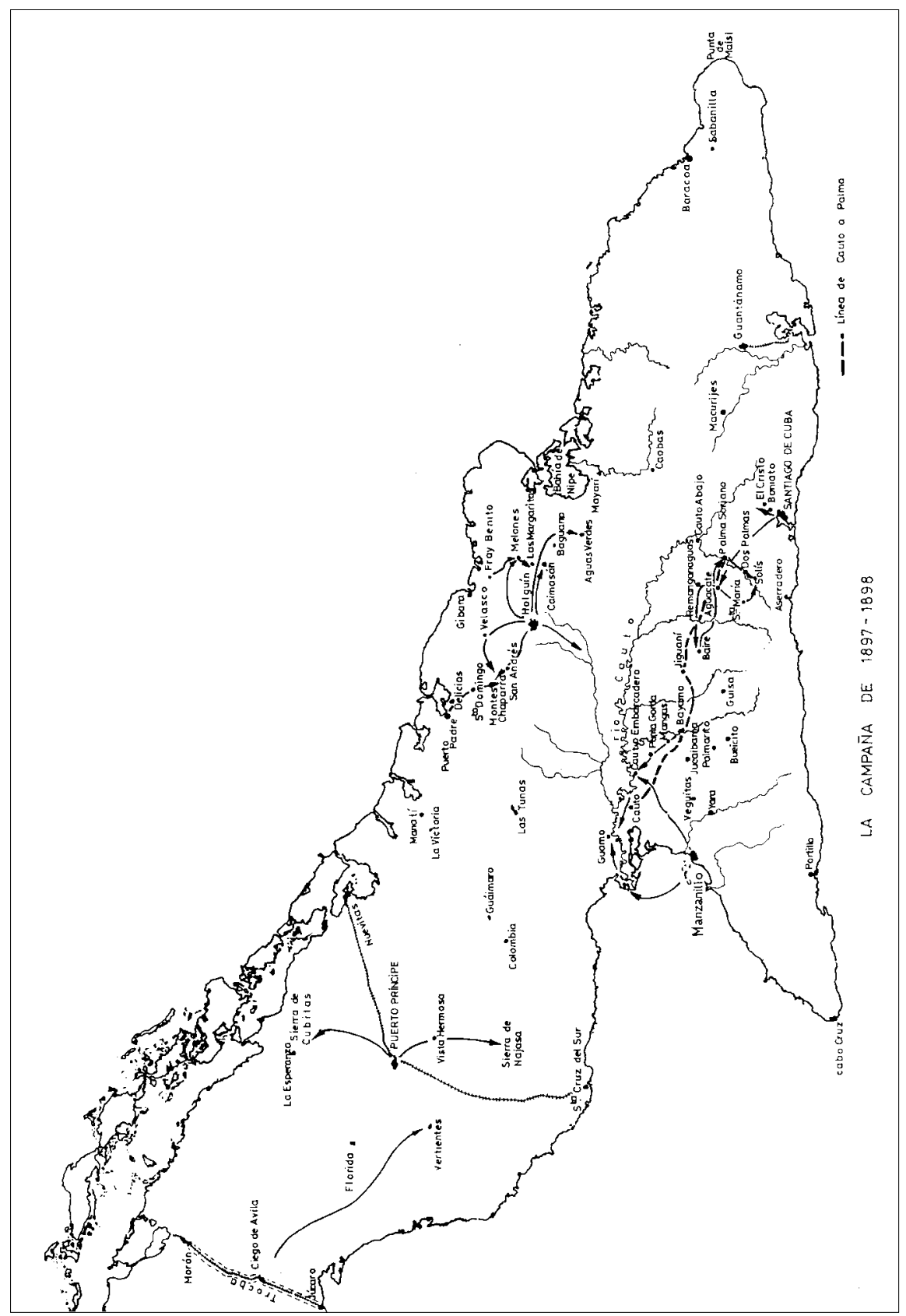

182 
La crisis de agosto se cerraba el 31 de octubre de 1897, con la llegada a La Habana del nuevo capitán general, don Ramón Blanco. Ya nada sería igual.

\section{Los últimos pasos hacia la victoria}

La nueva política preconizada por Sagasta incluía la continuación de las operaciones para someter la porción oriental de la isla --incluso enviando nuevas tropas de refuerzo- ${ }^{34}$ la tentativa de pacificación mediante el ofrecimiento de cantidades de dinero a los jefes rebeldes, la anulación de las órdenes de reconcentración, y la promesa, que se realizaría en breve, de una ley de autonomía para Cuba. Al mismo tiempo, se trataría de mantener a distancia al incómodo vecino de Washington, donde desde principios del año gobernaba el presidente McKinley.

No sería justo decir que la política de Sagasta fracasó, puesto que, lo mismo que a Cánovas y a Weyler, tampoco a él le fue dado el tiempo necesario para alcanzar sus objetivos. Ciertamente en el terreno militar, la labor de Blanco y del general Pando, su jefe de Estado Mayor, fue en cierto modo continuación de la de la etapa anterior frente a un enemigo que apenas presentaba resistencia. El 30 de agosto de 1897 había tomado Calixto García la población de Victoria de las Tunas, suceso lamentable pero de escasa trascendencia en un frente todavía secundario y cuando se preparaba la gran campaña de Oriente. Tres meses después, ya durante el mandato del general Blanco, tomó García en la misma provincia el pueblo de Guisa. Como los "invasores" de 1895, el general mambí había aprovechado en ambos casos, no solo la superioridad numérica, sino la de su artillería sobre modestas "fortificaciones" de tapia y tablas, eficaces sólo frente a la infantería. Ambos triunfos resultaron por otra parte manchados por las atrocidades cometidas contra los rendidos. ${ }^{35} \mathrm{Y}$ después de Guisa parece que Calixto pasa a la defensiva o a la inactividad.

34 En 1898 el ejército español de Cuba recibió un contingente de 16.924 hombres. Moreno Fraginals y José J. Moreno Masó, Manuel R.: Guerra, migración y muerte. (El ejército español en Cuba como vía migratoria), Barcelona, 1993, pág. 132. Estos autores toman el dato de un estudio inédito de César R. Yáñez Gallardo.

35 En Tunas, "los guerrilleros cautivos, casi todos cubanos y de la raza negra, fueron implacablemente pasados por el filo del terrible machete; era el criterio inflexible del general contra aquellos infelices asalariados, en gran parte cubanos". En Guisa, "los voluntarios y guerrilleros capturados fueron ejecutados inmediatamente”. Casasús, Juan J. E.: Calixto García (El estratega). La Habana, 1962, 2. ${ }^{a}$ ed. págs. 232 y 247. 
Mientras se completaba la pacificación de las provincias occidentales, Blanco y Pando podían concentrar el mayor esfuerzo sobre el reducto de Gómez, en La Reforma y, más aún, al otro lado de la trocha, en Camagüey y Oriente. Se advertiría, sin embargo, un ritmo más pausado en las operaciones y un cambio en el plan general de éstas. El traslado de tropas a Oriente no comenzaría hasta mediado noviembre, y no alcanzaría las proporciones que Weyler había anunciado. Por otra parte, descartado el proyecto de operar de este a oeste, empujando a los rebeldes contra la trocha, Pando comenzaría por la reconquista desde Manzanillo del valle del Cauto, acometida a principios de diciembre. Convertida Bayamo en base de operaciones, y establecida la línea Cauto-Bayamo-Jiguaní-Palma, desde febrero de 1898 se emprendieron campañas en el interior del territorio, en combinación con las fuerzas de Holguín, y hacia el sur, combinando con las de Santiago y Manzanillo, para expulsar a los insurrectos de Sierra Maestra, forzándolos a retirarse hacia las Tunas. Poco después "en la corta pero fructífera campaña del 18 de marzo al 9 de abril", dirá Pando, desde Puerto Príncipe las tropas atacaban la porción oriental de Camagüey, hostigando a los mambises en La Esperanza (Sierra Cubitas) y en la Najasa. ${ }^{36}$ De modo que, aunque tampoco ahora se lograse la muerte o captura de Gómez, casi inactivo en su escondite, la presencia del ejército español crecía de continuo en las regiones que fueron cuna de la insurrección y punto de partida de la "invasión". El ejército mambí se veía acosado en territorios que durante más de dos años había considerado suyos. Mientras consolidaban cada día el dominio sobre las provincias occidentales, las tropas españolas habían emprendido la ofensiva final contra Calixto García en Oriente.

En los primeros meses de 1898 todo apuntaba al triunfo definitivo de las armas españolas en plazo no muy largo, y esta sería la situación imperante hasta la suspensión unilateral de las hostilidades decidida por el gobierno español. Según lo expresó el capitán general Blanco, la ocupación de la línea del Cauto y las posteriores operaciones combinadas "determinaron un indiscutible progreso en el estado de la guerra separatista, que todo hacía creer terminaría en breve plazo"; se había producido "gran quebranto de la insurrección", de modo que "el enemigo, batido en sus principales refugios, apenas presentaba ya resistencia, recorriendo las tropas el

36 Escrito presentado por Pando ante el Senado, 22 de octubre de 1898. En Ortega Rubio, Juan: Historia de la Regencia de D. ${ }^{a}$ María Cristina de Habsbourg-Lorena, Madrid, 1905-1906, 5 vols., t. III, pág. 241. 
país en pequeñas columnas y acentuándose en él una saludable reacción favorable a la paz". ${ }^{37}$

Por eso, decir que el ejército mambí y Calixto García alcanzaron la victoria de 1898 es, cuando menos, una inexactitud nada leve. La sustitución de Weyler por Blanco hizo que se renunciase a la que pudiera haber sido la campaña final de la guerra, pero no significó la derrota de las tropas españolas por las cubanas, ni tal cosa podía considerarse ni remotamente previsible..$^{38}$

La tentativa de pacificación preconizada por Sagasta y Moret, en cambio, no podía dar frutos a corto plazo. No mientras los mambises se mantuvieran con las armas en la mano y negándose rotundamente a oír siquiera una propuesta de paz. Los intentos de ganar las voluntades de los jefes insurrectos, repitiendo la experiencia del Zanjón, fueron generalmente rechazados, y aunque se produjeron varias presentaciones, algunos de los enviados para parlamentar fueron asesinados por los rebeldes. Sin duda crecía entre los jefes mambises que aún resistían, aunque acorralados y en situación desesperada, la esperanza de que, con la desaparición de Cánovas y la destitución de Weyler, el dominio español sobre la isla tocaba a su fin.

Las medidas políticas buscaban aliviar tensiones. Entre ellas figuraba la de suprimir la concentración. A los que antes permanecían recluidos y a la vista de las guarniciones, y a los que se presentaban, se les dieron socorros en dinero y se les permitió volver a los campos y tener armas. Esto pudo influir en algún rebrote de las partidas.

Por otra parte, el ofrecimiento de la autonomía desde una posición considerada de debilidad tropezaba con algunas dificultades. Quienes en Cuba habían luchado del lado español no necesitaban la autonomía y muchos seguían oponiéndose a ella. Quienes venían enfrentándose contra

37 Certificación de los servicios prestados por el teniente general Pando. Madrid, 10 de julio de 1899. Discursos pronunciados por el Excmo. Sr. D. Luis M. de Pando los días 18, 19 y 26 de julio de 1899 en el Congreso de los Diputados... Madrid, 1899, págs. 14-15.

38 Foner, usando diversas referencias, plantea (I, págs. 183-184, en nota) la duda acerca de las tropas españolas existentes en la isla a finales de 1897 y comienzos de 1898. Weyler proporciona, sin embargo (V, pág. 42) el resumen de la fuerza existente el 10 de agosto de 1897: tropa del ejército en revista, 165.247 hombres (más 28.972 enfermos); voluntarios movilizados, 27.783 (más 919 enfermos). Da también el número de caballos (21.730, en total) y de acémilas (6.853). Más adelante recoge Weyler (Mi mando..., t. V, pág. 510), citando a Pando, que Blanco quiso movilizar 40.000 ó 50.000 hombres del país, con lo que en seis meses hubiera acabado la guerra, pero no le fueron concedidos los créditos precisos. "Terrible acusación — apostilla Weyler - para el gobierno liberal". El mismo Pando, en abril de 1898, cifra las fuerzas españolas en más de 200.000 hombres (Discursos..., pág. 18), mientras que el general Aldave precisa que son 185.000 en total, de los que sólo 71.000 disponibles (ibídem, pág. 19). 
España, no la aceptaban, pues no se conformarían con menos que la independencia. De todos modos el gobierno autónomo quedó instalado el $1 .^{\circ}$ de enero de 1898 y el parlamento insular el 4 de mayo. No sería aventurado suponer que, disponiendo de tiempo, el funcionamiento de estas instituciones hubiera podido dar un giro a la situación. Por el momento, junto con algunas deserciones del campo rebelde, fue perceptible alguna tensión entre asimilistas y autonomistas, mientras que cierta prensa se desataba en injurias contra los españoles, el ejército y los voluntarios. De estas provocaciones se derivaría el incidente que motivó la visita del "Maine" al puerto de La Habana.

\section{Rectificación de los juicios de Sagasta y su gobierno}

Con la intervención armada de los Estados Unidos, a los capitanes generales españoles les fue arrebatada la victoria sobre la insurrección, pero Weyler tuvo al menos la oportunidad de ver desautorizada muy pronto la campaña denigratoria de la que había sido víctima. En octubre de 1897, cuando aún no se había producido el relevo del capitán general, el gobierno de Sagasta dio por buenos los informes de Weyler cuya veracidad antes había puesto en duda. En la larga nota dirigida el 23 de octubre por el nuevo ministro de Estado, don Pío Gullón, al ministro plenipotenciario norteamericano se lee: "muy adelantada por el valiente esfuerzo de las armas españolas la pacificación de las provincias occidentales de la isla... la situación resulta muy diversa de cuando las huestes de Maceo y Máximo Gómez recorrieron las provincias de la Habana y Pinar del Río". Y en una nueva nota de $1 .^{\circ}$ de febrero de 1898 negó Gullón la acusación de posibles desmanes del ejército español, que durante cerca de tres años -incluyendo, por tanto, la época de Weyler- había actuado disciplinadamente, siendo algunos hechos lamentables consecuencia inevitable de la guerra. "Si como es de suponer — reflexiona Weyler- esta nota representaba el juicio del gobierno del Sr. Sagasta, bien pronto su partido había cambiado de modo de pensar, reconociendo el error de sus juicios y censuras en la oposición". ${ }^{39}$

Esto no obstante, todavía después de perdida la isla volvería el mismo Gullón a poner en duda ante el Senado la promesa de Weyler de acabar la

39 Weyler: Mi mando..., t. V, pág. 477. 
guerra de Cuba a corto plazo, mereciendo esta contundente réplica del Conde de Tejada de Valdosera:

"Me ha preguntado S. S. si soy lo bastante cándido para creer que el general Weyler concluiría la guerra... Ha manifestado S. S. que no comprendía en mi perspicacia que yo presumiese que el general Weyler iba a concluir la guerra. A eso no tengo que decir más que lo siguiente: pesará eternamente sobre el partido liberal, y la Historia de España registrará en sus páginas la responsabilidad del partido liberal, aconsejando a S. M. el cambio de Ministerio, provocando la crisis de octubre, sin dejar pasar el corto plazo que pedía aquel para terminar la guerra". ${ }^{40}$

Esa responsabilidad es indiscutible, como la de los sucesos que de aquel cambio de gobierno se derivaron inmediatamente. El cambio, sin embargo, podemos creer que no se hubiera producido - al menos, no en esa forma— ${ }^{41}$ de no haber ocurrido en agosto el asesinato de Cánovas, cualesquiera que fuesen sus inductores, abriendo o anticipando la posibilidad de relevar al capitán general de Cuba y de ensayar la política que la prensa y los jefes liberales venían reclamando en los meses anteriores.

40 Ibídem, pág. 432.

41 Cánovas había manifestado en su última conversación con el exministro Fabié, según cuenta el hijo de éste, su propósito de hacer un último esfuerzo hasta el final del año 1897, añadiendo: "si con el esfuerzo que hagamos no ha terminado la insurrección cubana de modo que no tengan más remedio que reconocerlo así los Estados Unidos, el 31 de diciembre daré paso al partido liberal para que resuelva el problema con una solución autonómica y yo me retiraré a mi casa", lo que no pasa de ser una declaración de intenciones. María Fabié, Antonio: Cánovas del Castillo (Su juventud. Su edad madura. Su vejez). Barcelona, 1928, pág. 354. 